\title{
"Portfolio optimization under mean-CVaR simulation with copulas on the Vietnamese stock exchange"
}

\begin{tabular}{|c|c|c|}
\hline AUTHORS & \multicolumn{2}{|l|}{ Dao Thi Thanh Binh (iD) } \\
\hline ARTICLE INFO & \multicolumn{2}{|c|}{$\begin{array}{l}\text { Le Tuan Anh and Dao Thi Thanh Binh (2021). Portfolio optimization under mean- } \\
\text { CVaR simulation with copulas on the Vietnamese stock exchange. Investment } \\
\text { Management and Financial Innovations, 18(2), 273-286. } \\
\text { doi:10.21511/imfi.18(2).2021.22 }\end{array}$} \\
\hline DOI & \multicolumn{2}{|c|}{ http://dx.doi.org/10.21511/imfi.18(2).2021.22 } \\
\hline RELEASED ON & \multicolumn{2}{|l|}{ Friday, 11 June 2021} \\
\hline RECEIVED ON & \multicolumn{2}{|l|}{ Tuesday, 04 May 2021} \\
\hline ACCEPTED ON & \multicolumn{2}{|l|}{ Wednesday, 09 June 2021} \\
\hline & \multicolumn{2}{|l|}{$((c)) \mathrm{EY}$} \\
\hline LICENSE & \multicolumn{2}{|c|}{$\begin{array}{l}\text { This work is licensed under a Creative Commons Attribution } 4.0 \text { International } \\
\text { License }\end{array}$} \\
\hline JOURNAL & \multicolumn{2}{|c|}{ "Investment Management and Financial Innovations" } \\
\hline ISSN PRINT & \multicolumn{2}{|l|}{$1810-4967$} \\
\hline ISSN ONLINE & \multicolumn{2}{|l|}{$1812-9358$} \\
\hline PUBLISHER & \multicolumn{2}{|c|}{ LLC "Consulting Publishing Company "Business Perspectives" } \\
\hline FOUNDER & \multicolumn{2}{|c|}{ LLC "Consulting Publishing Company "Business Perspectives" } \\
\hline & & 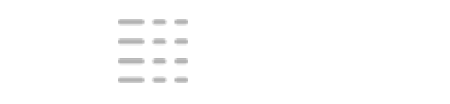 \\
\hline NUMBER OF REFERENCES & NUMBER OF FIGURES & NUMBER OF TABLES \\
\hline 26 & 6 & 6 \\
\hline
\end{tabular}

(C) The author(s) 2021. This publication is an open access article. 


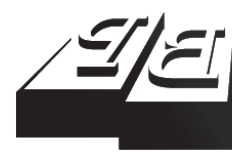

BUSINESS PERSPECTIVES

(O)

LLC "CPC "Business Perspectives"

Hryhorii Skovoroda lane, 10,

Sumy, 40022, Ukraine

www.businessperspectives.org

Received on: $4^{\text {th }}$ of May, 2021

Accepted on: $9^{\text {th }}$ of June, 2021

Published on: $11^{\text {th }}$ of June, 2021

() Le Tuan Anh, Dao Thi Thanh Binh 2021

Le Tuan Anh, MSc, Lecturer, Faculty of Finance and Banking, Dai Nam University, Vietnam. (Corresponding author)

Dao Thi Thanh Binh, Ph.D., Associate Professor, Lecturer, Faculty of Management and Tourism, Hano University, Vietnam.
Le Tuan Anh (Vietnam), Dao Thi Thanh Binh (Vietnam)

PORTFOLIO OPTIMIZATION

UNDER MEAN-CVAR SIMULATION WITH COPULAS ON THE VIETNAMESE STOCK EXCHANGE

\begin{abstract}
This paper studies how to construct and compare various optimal portfolio frameworks for investors in the context of the Vietnamese stock market. The aim of the study is to help investors to find solutions for constructing an optimal portfolio strategy using modern investment frameworks in the Vietnamese stock market. The study contains a census of the top 43 companies listed on the Ho Chi Minh stock exchange (HOSE) over the ten-year period from July 2010 to January 2021. Optimal portfolios are constructed using Mean-Variance Framework, Mean-CVaR Framework under different copula simulations. Two-thirds of the data from 26/03/2014 to 27/1/2021 consists of the data of Vietnamese stocks during the COVID-19 recession, which caused depression globally; however, the results obtained during this period still provide a consistent outcome with the results for other periods. Furthermore, by randomly at tempting different stocks in the research sample, the results also perform the same outcome as previous analyses. At about the same CvaR level of about $2.1 \%$, for example, the Gaussian copula portfolio has daily Mean Return of $0.121 \%$, the t copula portfolio has $0.12 \%$ Mean Return, while Mean-CvaR with the Raw Return portfolio has a lower Return at $0.103 \%$, and the last portfolio of Mean-Variance with Raw Return has 0.102\% Mean Return. Empirical results for all 10 portfolio levels showed that CVaR copula simulations significantly outperform the historical Mean-CVaR framework and Mean-Variance framework in the context of the Vietnamese stock exchange.
\end{abstract}

Keywords

JEL Classification Mean-Variance, portfolio optimization, Vietnam

C61, G11, G17

\section{INTRODUCTION}

In the world, the stock exchange was formed a long time ago, has grown strongly and has become a significant part of the global financial market. The stock market plays a vital role in the growth of industries in many countries that eventually affects the economy to a great extent. Realizing the importance of the stock exchange to the economy, the stock exchange in Vietnam has been officially operated since 2000. After 20 years, it has taken certain steps, providing new investment opportunities for both corporations and investors, as well as developing the financial market. The stock market has not only been noticeable but has become an integral part of socio-economic life; therefore, it has attracted many investors. Furthermore, the Vietnamese capital market is still primarily a stock market, with over $80 \%$ of capital flows being stocks.

The main objective of this study is to construct optimal portfolios and strategies for investors in the Vietnamese market. After that, the results of the research were conducted and solutions were provided to investors for more effective investment strategies. By doing these, the research will tend to answer the following questions: What are the optimal portfolio construction and investment strategies for inves- 
tors? How to develop and analyze the context and condition for constructing optimal portfolios in the Vietnamese market? The applicability of the Mean-CVaR framework and other modern investment theories in portfolio management in the Vietnamese stock market was evaluated.

This study contributes to the portfolio management literature. It provides an overall picture of optimal portfolio construction theories. In addition, it will lead several methods to obtain optimal portfolios based on different criteria of investors on the Vietnamese stock exchange. This study also consolidates the application of Mean-CVaR framework and Mean-Variance framework to the practical cases. Individual investors can be supported with more effective investment knowledge to limit risk and gain profits; at the same time, it is also beneficial for developing the Vietnamese stock market and improving the competitiveness of financial service providers in Vietnam.

\section{LITERATURE REVIEW}

\subsection{Mean-conditional value-at-risk framework}

The Markowitz Portfolio Framework (Markowitz, 1952) is known as the Mean-Variance Framework and the basement of Modern Portfolio Theory. Harry Markowitz first published this framework as Portfolio Selection in the Journal of Finance in 1952. In 1959, he published a book with the same title formally published his theory (Markowitz, 1959). The traditional investment methods mainly focus on predicting the trend of price movements of securities based on the use of basic and technical analysis methods. Markowitz developed a method that focuses on building a portfolio of multiple assets based on a combination of risk and return.

The Markowitz Portfolio Framework remained a cornerstone in the modern portfolio optimization theory by its initial mathematical application in constructing an optimal portfolio by quantitative methods. However, the variance in this framework is only efficient in measuring the symmetric risks of financial instruments. In fact, the distribution of many kinds of securities in the market is not symmetric, so that the variance factor is not appropriately an adequate risk measurement factor for these kinds of financial assets. Value-at-Risk (VaR) measurement is one of the most popular risk measurement factors to estimate the downside risk of financial instruments, and this factor is widely used by financial institutions, banking, investors, and practitioners. However, many studies proved the non-efficiency of VaR in optimizing investment portfolio because of mathematical problems such as non-subadditivity or non- con- vexity (Rockafellar et a., 2000; Artzner, 1999; Kolm et al., 2014). On the other hand, Conditional Value at risk has been recently submitted as an effective risk measurement factor to measure downside risks of the assets with asymmetric return distribution. The efficient application and the trustworthiness of CVaR outperform the VaR that can be easily seen by the replacement of risk measurement of Basel III from VaR to CVaR.

From the perspective of optimizing investment portfolio, Rockafellar et al. (2000) developed a framework of minimizing CVaR under the condition of the given minimum portfolio expected return. In their research, the Mean-CVaR optimization framework demonstrates that the convex programming problem can be reduced by the framework and can be solved as a linear programming problem. In other studies, this framework has been applied and developed in different constraints such as the work of Krokhmal et al. (2002), which examined this framework under multiple constraints; the application of Mean-CVaR for portfolios of derivative assets (Alexander et al., 2006); optimizing the portfolio Mean-CVaR framework with copulas (Kakouris \& Rustem, 2013); the extended framework of Mean-CVaR with transaction costs factor (Chen et al., 2012).

Compared to the traditional Mean-Variance framework, the Mean-CVaR framework has also theoretically and practically proven the best performance among studies. In fact, one of the most obvious evidences that makes the Mean-Variance framework not appropriate in terms of measuring risks is the underestimation of this framework to downside risks. Actual return distributions of financial instruments are non-normal or asymmet- 
ric with tails, skewness or kurtosis, and the Mean$\mathrm{CVaR}$ framework can solve these problems. Many studies have concluded that the Mean-CVaR framework has better performance in allocating financial assets in the portfolio than the MeanVariance framework (Topaloglou et al., 2002; Andersson et al., 2001). Chen et al. (2012) also stated that the adaption of linear optimization is more robust than the quadratic optimization of the traditional Markowitz Mean-Variance framework.

\subsection{Empirical studies of the mean-CVaR framework}

Dao (2014) conducted one of the first studies to apply the Mean-CVaR framework to optimize a portfolio of options. The study examined the target population of derivative financial instruments with four correlated assets, two calls, and two puts. The results have shown that the optimization in the context of CVaR, the efficient frontier in this case, is the most convex and smooth. In contrast, the non-convexities were found in the context of using VaR and Standard Deviations as risk measurements. Therefore, the Mean-Variance framework was once again confirmed by empirical application with different types of financial assets, especially in relation to options in this case.

Nguyen et al. (2018) conducted a study to give a precise answer of Does Mean-CVaR outperform Mean-Variance in both theoretical and practical perspectives. The study examined the performance of these two frameworks for the whole stocks in the US market in almost a century, from 1926 to 2006. The research analysis shows the better performance of the Mean-CVaR framework compared to the Mean-Variance framework by the influence of different features of stock returns such as means, volatilities, skewness, and kurtoses. Furthermore, by comparing these two frameworks under different market conditions, the Mean-CVaR framework also shown a positive effect in distress markets. However, the benefits of Mean-CVaR significantly decrease when the study considers some practical factors such as transaction costs.

Iyengar et al. (2009) provided a fast gradient descent method for Mean-CVaR optimization. The research financial instrument universe consists of treasury bonds with a maturity of $2,5,10$, and 30 years. The results of this research once again proved the efficiency of the Mean-CVaR framework in the empirical context and provided an alternative algorithm to the linear programming approach to solve this framework with a larger target population. This study is also an evidence of appropriately applying the Mean-CVaR optimization in a specific financial asset, which is a treasury bond.

Hafsa (2015) examined the application of the Mean-CVaR framework on the French market. The study investigated the target population of daily data of 20 stocks of the SBF 250 index listed companies from 2005 to the end of the year 2009. The results of this study have shown a positive impact of the Mean-CVaR framework in terms of the relationship between mean returns and the return-to-CVaR ratio. The empirical examination of the study also showed the significant impact of this framework to the financial crisis on the capital market. In addition, the performance of the Mean-CVaR framework in this specific market is also affected by the non-normality of financial assets such as the skewness and the kurtosis of these assets.

In contrast with previous studies supporting the Mean-CVaR approach, Lim et al. (2009) conducted a research to show the fragility of $\mathrm{CVaR}$ as a risk measurement factor in portfolio optimization. The sample data of this research are five stocks that have multivariate return distribution from August 3, 1984 to June 1, 2009. Due to the estimation errors of CVaR and the mean, the study showed that the portfolio optimization framework such as Mean-CVaR or global CVaR is unreliable in some specific contexts. This problem occurs when the tail of return distribution is getting heavier. However, the sample universe of this research is quite small, with only five stocks; therefore, the conclusion of this research needs to be examined by further empirical studies to prove the research statements.

$\mathrm{Hu}$ (2012) empirically compared three approaches to portfolio selection such as Mean-Variance, Minimum Covariance Determinant Robust Mean-Variance, and Mean-CVaR framework. The research target population consists of ten stocks 
listed in the Shanghai Securities Composite Index 50 according to the composite score. The results of the study have shown that the CVaR approach has better practicability than the remaining two frameworks due to the wide selection of financial assets with different return distributions. Furthermore, the Mean-CVaR framework has also shown a more comparative result in terms of optimizing portfolio under global minimum risk portfolio and tangency portfolio conditions.

Zhang (2016) conducted the first research about optimization with the Mean-CVaR framework for multiple portfolios instead of a single portfolio. The numerical results of the study have shown that the performance of Mean-CVaR to multiple portfolios is relatively better than the individual portfolio in terms of improvement rate from independent optimization. Additionally, the research has also shown that the Mean-CVaR framework supports the multi portfolios to reduce the market impact cost than the independent decision. The contribution of this research is significantly important, since it has extended the application and the development of the Mean-CVaR framework.

Isaksson (2016) examined the robust portfolio optimization with Expected shortfall (CVaR) with the worst cases and ellipsoidal uncertainty sets of data. The results exposed a clear advantage of Mean-Expected Shortfall framework asymmetric log-return distribution over the Mean-Variance optimization. However, the study also indicated that the Expected Shortfall approach has a problem of statistical uncertainty when processing the $\log$ data instead of the numerical format of data.

He et al. (2007) progressed a research about measuring the coupled risks like market and credit risks by CVaR model integrated with copulas. The numerical analysis took 13 listed stocks in the Chinese security market to be the target sample for research. It was indicated that the copula-based CVaR model can measure exactly the coupled risk in this financial market and can calculate the precise results of total risks of companies with bad credit risks. Therefore, with a complementary factor such as copulas simulation to the CVaR framework, investors can effectively prevent total risks of the financial stocks on the market and take wiser actions.
Kakouris et al. (2013) published an article about robust portfolio optimization with copulas to compare the efficiency of the Worst-case CVaR framework with CVaR Gaussian copula simulation and Worstcase Markowitz framework. The research took an analysis with seven indices: Nikkei225, FTSE100, Nasdaq, DAX30, Sensex, Bovespa, and Gold index, respectively, in Japan, UK, USA, Germany, India and Brazil from 1998 to 2011. This research sample not only consists of stocks and indices, but also has one commodity index. The results showed that their worst case CVaR framework with copulas had better performance than using Gaussian copula CVaR or worst-case Markowitz only.

Trabelsi et al. (2019) conducted a research using copula approach of generalized Pareto distribution to utilize the market-risk optimization with the CVaR measure among the developed and emerging markets. The research sample consists of the G7, BRICS, and 14 popular emerging stock-market returns from 1997 to 2008. The results showed that the portfolios in the CVaR efficient frontier of simulating returns with copulas outperform both the risks and returns of domestic portfolios like US stocks. Furthermore, the copula simulation gives more proper results than historical simulation. In addition, applying copula simulation for stocks in the global level portfolio showed nearly similar returns between Gaussian copula-based portfolios and $t$ copula-based portfolios. However, this application only tested the results for international portfolio diversification but not in a specific market; so, it is necessary to conduct another research to assess and consolidate the application of copula simulation to a specific market.

In the context of Vietnam's stock market, Nguyen et al. (2019) proposed an empirical research on measuring stock price volatility of $\mathrm{VN}$-index by applying symmetric models (GARCH, GARCH-M) and asymmetric models (EGARCH, TGARCH). Time series data of the study is the daily price of this index from March 1, 2001 to March 1, 2019. The results showed that the asymmetric volatility increases market risk, which makes the stocks become more attractive and affects the future movement of these stocks.

Nguyen et al. (2020) applied a linear shrinkage model to optimize the portfolio selection. The study took a research sample of listed companies on the Ho 
Chi Minh stock exchange without the IPO companies, and the research period was 468 weeks, from January 2011 to December 2019. The results proposed that the shrinkage framework rendered portfolios with higher returns and lower level of risk compared to the traditional sample covariance matrix. In addition, the low portfolio turnover in this model can be an advantage in reducing the liquidity risk.

The main purpose of this research is to construct the optimal portfolios for investors in the context of the Vietnamese market by applying the research methods that will be presented in the next session. Despite proposing a variety of studies on this topic, some particular gaps need to be filled, especially in the empirical case of the Vietnamese market; other research used different types of models to optimize portfolios in the context of Vietnam, such as the work of Nguyen et al. (2019) and Nguyen et al. (2020), but this is one of the first studies to apply $\mathrm{CVaR}$ frameworks and copulas simulation in this particular market, which contributes to the novelty of this paper. By applying various mathematical and financial models such as the Markowitz Mean-Variance model, Mean-CVaR framework, and copulas simulation, this study aims to obtain optimal portfolios and forecast the risks of these portfolios based on the CVaR. The hypothesis of this paper is that Mean-CVaR portfolios with copula simulations outperform traditional MeanVariance portfolios and Mean-CvaR portfolios without simulation.

\section{METHODOLOGY}

This study applies the descriptive research method to construct optimal portfolios and strategies for investors in the context of the Vietnamese market. By applying mathematical and financial models such as the Markowitz Mean-Variance model, Mean-CVaR framework, and copulas simulation, the study will proceed to find out optimal portfolios for individual investors and forecast the risks of these portfolios based on the Variance, CVaR calculation.

The study includes the top 43 companies listed on the Ho Chi Minh Stock Exchange (HOSE). The research period is ten years from July 2010 to
January 2021. The data is collected, presented and processed by the data analytical tool Solver, and Matlab R2020b to calculate the required factors in the model, as well as the matrices between related factors, simulations, and frameworks needed for the empirical analysis.

\subsection{Theoretical framework assumptions}

At the given time horizon $\mathrm{t}>0$, the study assumes that: The price of stocks in the portfolio is $S_{t} \in N$; The initial price of stocks in the portfolio is $S_{0}$; $x_{1}, x_{2}, \ldots, x_{n}$ are the weight of stocks in the portfolio; $r_{1}, r_{2}, \ldots, r_{n}$ are the return of stocks in the portfolio, with $r_{i}=\left(S_{t}-S_{0}\right) / S_{0} ; E\left(R_{p}\right)$ (expected return of the portfolio), $\sigma_{p}^{2}$ (variance), $\sigma_{p}$ (standard deviation), and CVaR (conditional value at risk) are the factors to derive an optimal portfolio. There is no transaction costs and taxes in the theoretical frameworks, and the optimal value of the portfolio is determined by Mean-CVaR framework and Mean-Variance framework.

The variance of the portfolio (Variance-Covariance Matrix) is proposed as follows:

$$
\sigma_{p}^{2}=\left(x_{1}, x_{2}, \ldots, x_{n}\right)\left(\begin{array}{ccc}
\operatorname{Cov}_{11} & \ldots & \operatorname{Cov}_{1 n} \\
\vdots & \ddots & \vdots \\
\operatorname{Cov}_{n 1} & \ldots & \operatorname{Cov}_{n n}
\end{array}\right)\left(\begin{array}{c}
x_{1} \\
x_{2} \\
\ldots \\
x_{n}
\end{array}\right) .
$$

Standard deviation of a portfolio is the square root of variance of the portfolio.

The linear correlation matrix is the matrix of paired stocks of the correlations and is defined as follows:

$$
\rho_{p}=R=\left(\begin{array}{ccc}
\vartheta_{11} & \ldots & \vartheta_{1 n} \\
\vdots & \ddots & \vdots \\
\vartheta_{n 1} & \ldots & \vartheta_{n n}
\end{array}\right) .
$$

\subsection{Gaussian copula and t copula approach}

The Gaussian copula and $t$ copula are two copulas in the Elliptical copula family, and these two copulas are used in this study to simulate the return of stocks before putting into the Mean-CVaR framework to find the optimal portfolios. 


\subsubsection{Gaussian copula}

Gaussian copula is the copula of the multivariate normal distribution, and it can be obtained as follows:

$$
\begin{aligned}
& C\left(u_{1}, \ldots, u_{n} ; R\right)= \\
& =\phi^{k}\left(\phi^{-1}\left(u_{1}\right), \ldots, \phi^{-1}\left(u_{n}\right) ; R\right),
\end{aligned}
$$

where $\phi^{k}$ is the standard multivariate normal distribution; $\phi^{-1}$ is the inverse of the standard univariate normal distribution function $\varphi$; and $R$ is the linear correlation matrix.

The density of the Gaussian copula is:

$$
\begin{aligned}
& C\left(u_{1}, \ldots, u_{n} ; R\right)= \\
& =\frac{1}{|R|^{\frac{1}{2}}} \exp \left(-\frac{1}{2} \omega^{T}\left(R^{-1}-1\right) \omega\right),
\end{aligned}
$$

with $\omega=\left(\phi^{-1}\left(u_{1}\right), \ldots, \phi^{-1}\left(u_{n}\right)\right)^{T} ; R$ is the linear correlation matrix.

\subsection{2. t Copula}

$t$ copula is the Gaussian copula with cumulative distribution functions (CDF), and it employs the multivariate Student's $t$ distribution, allowing fatter tails. The formula is defined as follows:

$$
\begin{aligned}
& C_{n}^{\psi}(u ; R ; v)= \\
& =\psi_{n}\left(\psi^{-1}\left(u_{1} ; v\right), \ldots, \psi^{-1}\left(u_{n} ; v\right) ; R, v\right) .
\end{aligned}
$$

where $\psi_{n}$ is the CDF of an $n$-variate Student's $t$ distribution with $R$ correlation; $v$ is the degree of freedom parameters, and $v>2 ; \psi^{-1}$ is the inverse of the CDF for univariate Student's $t$ distribution with mean zero and dispersion parameter equals to 1 .

The density of $t$ copula is: where $\omega=\left[\psi^{-1}\left(u_{1} ; v\right), \ldots, \psi^{-1}\left(u_{n} ; v\right)\right]^{T} ; \Gamma($.$) is$ the gamma function.

\subsection{Mean-CVaR optimal portfolio} framework

This study follows the framework of Rockafellar and Uryasev $(2000,2002)$, and Krokhmal et al. (2002) to minimize the CVaR of a portfolio under the given expected return.

According to Rockafellar and Uryasev (2000), $f(x ; y)$ is the loss associated with the decision vector $x$ (to be chosen from a certain subset $X \in R^{n}$ ), and the random vector $y$ (from $R^{m}$ ).

Denote that Vector $x$ is a portfolio in $X$ available portfolios, and Vector $y$ is the uncertainties that can affect the loss (e.g.: the market parameters,...). With each $x$, the loss $f(x ; y)$ is a random variable with a distribution in $R$, including by that of $y$. The underlying probability distribution of $y$ from $R^{m}$ is denoted by $p(y)$, and have a density.

The probability that $f(x ; y)$ does not exceed the threshold $\alpha$ is:

$$
\psi(x, \alpha)=\int_{f(x, y) \leq \alpha} p(y) \cdot d(y) .
$$

$\psi(x, \alpha)$ is the cumulative distribution function for the loss associated with $x$. It is assumed that there is no jump, and $\psi(x, \alpha)$ is everywhere continuous with respect to $\alpha$. The formula for Value at $\operatorname{Risk}\left(\alpha_{\beta}\right)$ is as follows:

$$
\alpha_{\beta}(x)=\min \{\alpha \in R: \psi(x, \alpha) \geq \beta\} .
$$

The approach to CVaR at a confidence level $\beta^{1}$ can be obtained through the $\operatorname{VaR}\left(\alpha_{\beta}\right)$ :

$$
\begin{aligned}
& F_{\beta}\left(x, \alpha_{\beta}\right)=\alpha_{\beta}+ \\
& +\frac{1}{1-\beta} \cdot \int_{r \in R^{N}}\left[-x^{\prime} r-\alpha_{\beta}\right]^{+} p(r) d r,
\end{aligned}
$$

$$
C_{n}^{\psi}(u ; R ; v)=\frac{\Gamma\left(\frac{v+n}{2}\right)\left[\Gamma \frac{v}{2}\right]^{n}\left(1+\omega^{T} R^{-1} \omega\right)^{\frac{-(v+n)}{2}}}{|R|^{\frac{1}{2}} \Gamma\left(\frac{v}{2}\right)\left[\Gamma\left(\frac{v+1}{2}\right)\right]^{n} \prod_{i=1}^{n}\left(1+\frac{\omega_{i}^{2}}{v}\right)^{\frac{-(v+1)}{2}}},
$$

1 It is a confidence level, in this case the confidence level of a portfolio that it will not exceed the expected loss usually takes values at $95 \%$ or $99 \%$. 
where $\alpha_{\beta}$ is the corresponding Value-at-Risk of the CVaR; $\beta$ is the level of confidence of CVaR; $x=\left(x_{1}, x_{2}, \ldots, x_{n}\right)^{\prime}$ is the weight of $\mathrm{n}$ assets in the portfolio; $r=\left(r_{1}, r_{2}, \ldots, r_{n}\right)^{\prime}$ is the return of $n$ assets in the portfolio; $p(r)$ is the probability density function of the above return variables; $[t]^{+}$is the function that takes value $t$ when $t \geq 0$, otherwise $[t]^{+}=\max [t ; 0]$.

Therefore, minimizing CVaR with respect to $x$ is equivalent to minimizing the $F_{\beta}\left(x, \alpha_{\beta}\right)$ with respect to $\left(x, \alpha_{\beta}\right)$ and minimizing $\phi_{\beta}(x)$ which is equal to $F_{\beta}\left(x, \alpha_{\beta}\right)-\alpha_{\beta}$ :

$$
\begin{aligned}
& C V \alpha R_{\beta}(x)=\min _{x \in X} \phi_{\beta}(x)= \\
& =\min _{\left(x, \alpha_{\beta}\right) \in X \cdot R} F_{\beta}\left(x, \alpha_{\beta}\right),
\end{aligned}
$$

where $X$ is the set of possible choices for $x$.
The framework is presented as follows:

$$
\min \phi_{\beta}(x)
$$

with:

$$
E_{r p} \geq r^{*}
$$

$r^{*}$ is the given Expected Return:

$$
\begin{gathered}
\sum_{i=1}^{n} x_{i}=1, \\
x_{i} \geq 0 .
\end{gathered}
$$

By proposing the theoretical frameworks, the

\begin{tabular}{|c|c|c|c|c|c|c|c|c|}
\hline \multirow{2}{*}{$\begin{array}{l}\text { Portfolio } \\
\text { number }\end{array}$} & \multicolumn{2}{|c|}{$\begin{array}{c}\text { Mean-CVaR under Gaussian } \\
\text { copula simulation }\end{array}$} & \multicolumn{2}{|c|}{$\begin{array}{l}\text { Mean-CVaR under } t \\
\text { copula simulation }\end{array}$} & \multicolumn{2}{|c|}{$\begin{array}{c}\text { Mean-CVaR } \\
\text { with raw return }\end{array}$} & \multicolumn{2}{|c|}{$\begin{array}{l}\text { Mean-variance } \\
\text { with raw return }\end{array}$} \\
\hline & Mean return & 95\% CVaR & $\begin{array}{l}\text { Mean } \\
\text { return }\end{array}$ & 95\% CVaR & $\begin{array}{l}\text { Mean } \\
\text { return }\end{array}$ & 95\% CVaR & $\begin{array}{l}\text { Mean } \\
\text { return }\end{array}$ & 95\% CVaR \\
\hline 1 & $0.052 \%$ & $1.447 \%$ & $0.036 \%$ & $1.602 \%$ & $0.036 \%$ & $1.489 \%$ & $0.034 \%$ & $1.519 \%$ \\
\hline 2 & $0.069 \%$ & $1.485 \%$ & $0.057 \%$ & $1.641 \%$ & $0.053 \%$ & $1.533 \%$ & $0.051 \%$ & $1.565 \%$ \\
\hline 3 & $0.087 \%$ & $1.577 \%$ & $0.078 \%$ & $1.749 \%$ & $0.069 \%$ & $1.659 \%$ & $0.068 \%$ & $1.690 \%$ \\
\hline 4 & $0.104 \%$ & $1.755 \%$ & $0.099 \%$ & $1.939 \%$ & $0.086 \%$ & $1.873 \%$ & $0.085 \%$ & $1.895 \%$ \\
\hline 5 & $0.121 \%$ & $2.100 \%$ & $0.120 \%$ & $2.198 \%$ & $0.103 \%$ & $2.148 \%$ & $0.102 \%$ & $2.160 \%$ \\
\hline 6 & $0.139 \%$ & $2.641 \%$ & $0.140 \%$ & $2.559 \%$ & $0.119 \%$ & $2.464 \%$ & $0.119 \%$ & $2.472 \%$ \\
\hline 7 & $0.156 \%$ & $3.355 \%$ & $0.161 \%$ & $2.995 \%$ & $0.136 \%$ & $2.835 \%$ & $0.135 \%$ & $2.836 \%$ \\
\hline 8 & $0.173 \%$ & $4.546 \%$ & $0.182 \%$ & $3.570 \%$ & $0.153 \%$ & $3.427 \%$ & $0.152 \%$ & $3.445 \%$ \\
\hline 9 & $0.190 \%$ & $6.718 \%$ & $0.203 \%$ & $4.560 \%$ & $0.169 \%$ & $5.425 \%$ & $0.169 \%$ & $5.396 \%$ \\
\hline 10 & $0.208 \%$ & $9.477 \%$ & $0.224 \%$ & $6.562 \%$ & $0.186 \%$ & $9.389 \%$ & $0.186 \%$ & $9.389 \%$ \\
\hline
\end{tabular}
study provides a clear methodology for how the research will be conducted, and the empirical analysis of the study will be applied to these theoretical frameworks.

Table 1. Mean returns and $95 \% \mathrm{CVaR}$ of 10 portfolios in each case

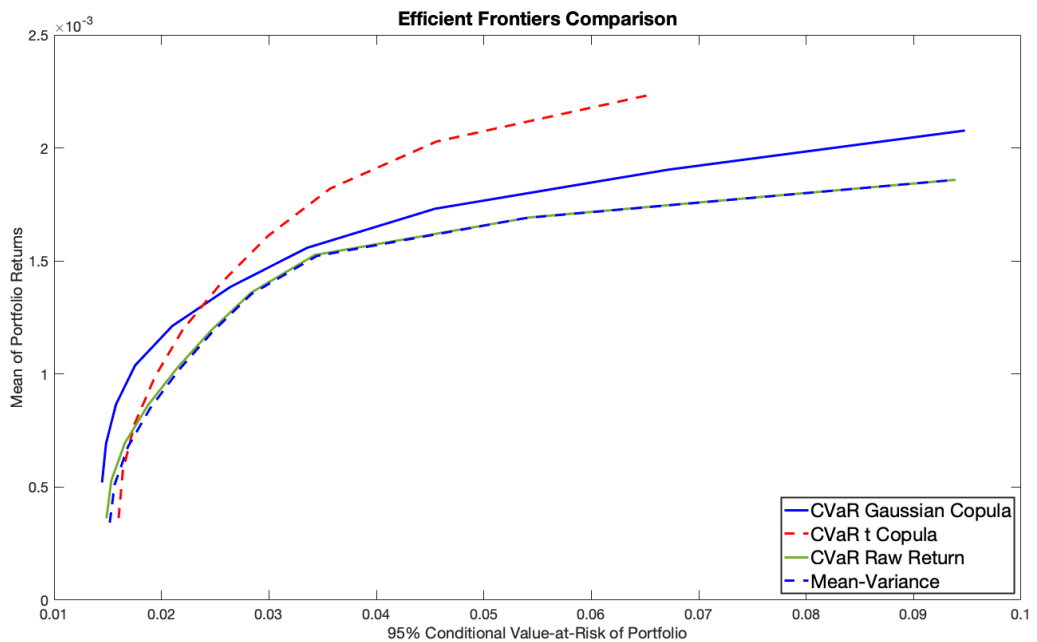

Figure 1. Mean-CVaR efficient frontiers with the $95 \% \mathrm{CVaR}$ 


\section{EMPIRICAL RESULTS AND DISCUSSION}

\subsection{Portfolio optimization with $95 \%$ of conditional value at risk}

With the data input of full 43 stocks, the study estimates a $95 \%$ CVaR of ten different portfolios in each case based on the given return of each portfolio and the constraints given above.

Figure 1 presents the results given in Table 1 to plot the $95 \%$ efficient frontiers of four cases. It can be observed that the frontiers of CVaR optimization with simulations give better results than the frontiers optimized with the raw data input. Furthermore, most of the portfolios optimized with $t$ copula simulation show the best results with higher mean returns with the same $95 \% \mathrm{CVaR}$ as other portfolios in other cases. However, in the beginning of the frontiers, the portfolios in the Gaussian copula simulation frontier have better results than other portfolios with higher returns and low 95\% CVaR level. Another worth noting point is that the frontier of CVaR optimization with raw return is always higher than the frontier of Mean-Variance optimization. The overall trend of these results is that CVaR frontiers are better than the Mean-Variance frontier; the portfolios optimized with the Mean-CVaR framework and simulated with copulas are more superior than the those optimized with raw return.

To make the results more reliable, the study applies similar frameworks on two-thirds of the da-

Table 2. Mean returns and $95 \% \mathrm{CVaR}$ of 10 portfolios in each case (6.5-year duration)

\begin{tabular}{|c|c|c|c|c|c|c|c|c|}
\hline \multirow{2}{*}{$\begin{array}{l}\text { Portfolio } \\
\text { number }\end{array}$} & \multicolumn{2}{|c|}{$\begin{array}{c}\text { Mean-CVaR under Gaussian } \\
\text { copula simulation }\end{array}$} & \multicolumn{2}{|c|}{$\begin{array}{l}\text { Mean-CVaR under } t \\
\text { copula simulation }\end{array}$} & \multicolumn{2}{|c|}{$\begin{array}{c}\text { Mean- CVaR } \\
\text { with raw return }\end{array}$} & \multicolumn{2}{|c|}{$\begin{array}{l}\text { Mean-variance } \\
\text { with raw return }\end{array}$} \\
\hline & Mean return & 95\% CVaR & $\begin{array}{l}\text { Mean } \\
\text { return }\end{array}$ & 95\% CVaR & $\begin{array}{l}\text { Mean } \\
\text { return }\end{array}$ & 95\% CVaR & $\begin{array}{l}\text { Mean } \\
\text { return }\end{array}$ & $95 \%$ CVaR \\
\hline 1 & $0.052 \%$ & $1.218 \%$ & $0.042 \%$ & $1.226 \%$ & $0.047 \%$ & $1.222 \%$ & $0.039 \%$ & $1.283 \%$ \\
\hline 2 & $0.074 \%$ & $1.240 \%$ & $0.082 \%$ & $1.306 \%$ & $0.066 \%$ & $1.271 \%$ & $0.059 \%$ & $1.287 \%$ \\
\hline 3 & $0.097 \%$ & $1.308 \%$ & $0.122 \%$ & $1.480 \%$ & $0.085 \%$ & $1.399 \%$ & $0.079 \%$ & $1.395 \%$ \\
\hline 4 & $0.119 \%$ & $1.435 \%$ & $0.162 \%$ & $1.723 \%$ & $0.104 \%$ & $1.601 \%$ & $0.099 \%$ & $1.599 \%$ \\
\hline 5 & $0.141 \%$ & $1.612 \%$ & $0.202 \%$ & $2.037 \%$ & $0.124 \%$ & $1.866 \%$ & $0.119 \%$ & $1.872 \%$ \\
\hline 6 & $0.164 \%$ & $1.867 \%$ & $0.241 \%$ & $2.434 \%$ & $0.143 \%$ & $2.181 \%$ & $0.139 \%$ & $2.184 \%$ \\
\hline 7 & $0.186 \%$ & $2.260 \%$ & $0.281 \%$ & $2.963 \%$ & $0.162 \%$ & $2.559 \%$ & $0.159 \%$ & $2.574 \%$ \\
\hline 8 & $0.209 \%$ & $2.776 \%$ & $0.321 \%$ & $3.690 \%$ & $0.181 \%$ & $3.021 \%$ & $0.179 \%$ & $3.043 \%$ \\
\hline 9 & $0.231 \%$ & $3.654 \%$ & $0.361 \%$ & $4.693 \%$ & $0.200 \%$ & $3.676 \%$ & $0.200 \%$ & $3.713 \%$ \\
\hline 10 & $0.253 \%$ & $6.308 \%$ & $0.401 \%$ & $6.283 \%$ & $0.220 \%$ & $5.842 \%$ & $0.220 \%$ & $5.842 \%$ \\
\hline
\end{tabular}

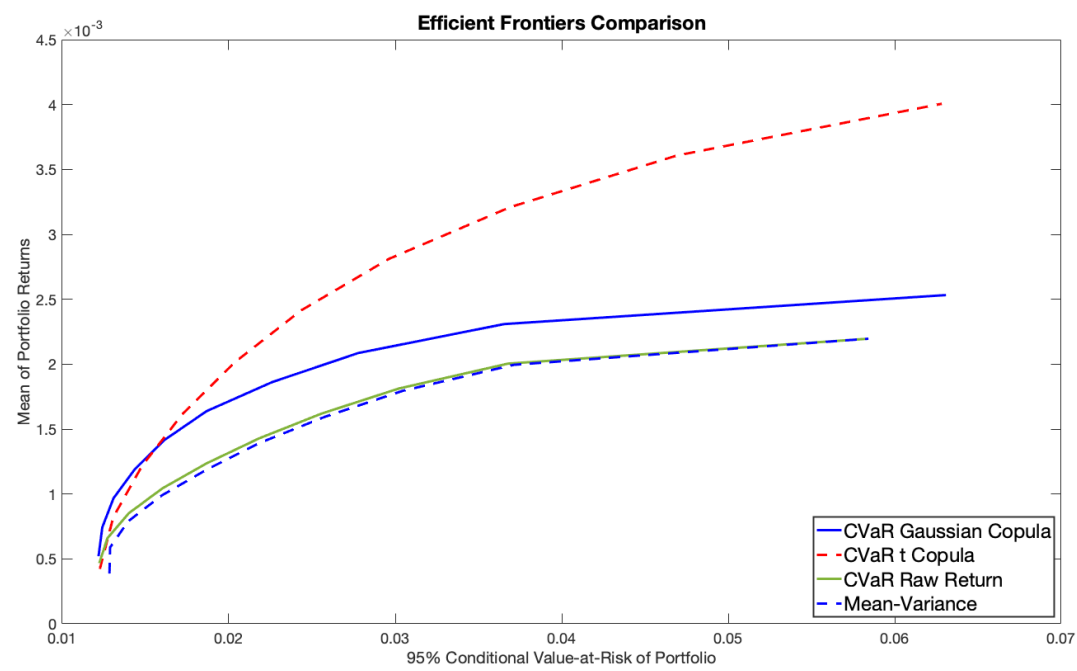

Figure 2. Mean-CVaR efficient frontiers with 95\% CVaR (6.5-year duration) 
ta (which is about 6.5 years) and on 23 random stocks in 43 stocks to test the reliability of the research results.

Table 2 and Figure 2 show the results of applying simulations, Mean-CVaR framework, and MeanVariance framework on two-thirds of the data from $26 / 03 / 2014$ to $27 / 1 / 2021$.

In the shorter period, the results are similar to the above results of the research that the highest efficient frontier is $t$ copula $\mathrm{CVaR}$, followed by Gaussian copula CVaR frontier, CVaR frontier with raw return and Mean-Variance frontier. CVaR portfolios simulated with $t$ copula and CVaR portfolios simulated with Gaussian copula still outperformed the portfolios optimized by historical raw return CVaR framework or Mean-
Variance framework. For investors with low-risk preference, the Gaussian copula CVaR portfolios are the best choices with higher returns than portfolios in other models and the low CVaR level. Likewise, the above results, the frontier of CVaR optimization with raw return is always higher than the frontier of Mean-Variance optimization.

Additionally, Table 3 and Figure 3 are the results of the optimizational models of 23 random stocks selected from the research sample of 43 stocks.

Similarly to the two previous results above, the efficient frontier of $t$ copula CVaR still has the best overall results compared to other frontiers. Also, in this example, the frontier trends exactly match the tendencies of frontiers in the

Table 3. Mean returns and $95 \%$ CVaR of 10 portfolios in each case (23 random stocks)

\begin{tabular}{|c|c|c|c|c|c|c|c|c|}
\hline \multirow{2}{*}{$\begin{array}{l}\text { Portfolio } \\
\text { number }\end{array}$} & \multicolumn{2}{|c|}{$\begin{array}{c}\text { Mean-CVaR under Gaussian } \\
\text { copula simulation }\end{array}$} & \multicolumn{2}{|c|}{$\begin{array}{l}\text { Mean-CVaR under } t \\
\text { copula simulation }\end{array}$} & \multicolumn{2}{|c|}{$\begin{array}{c}\text { Mean- CVaR } \\
\text { with raw return }\end{array}$} & \multicolumn{2}{|c|}{$\begin{array}{l}\text { Mean-variance } \\
\text { with raw return }\end{array}$} \\
\hline & Mean return & 95\% CVaR & $\begin{array}{l}\text { Mean } \\
\text { return }\end{array}$ & 95\% CVaR & $\begin{array}{l}\text { Mean } \\
\text { return }\end{array}$ & 95\% CVaR & $\begin{array}{l}\text { Mean } \\
\text { return }\end{array}$ & $95 \%$ CVaR \\
\hline 1 & $0.038 \%$ & $1.916 \%$ & $0.032 \%$ & $1.830 \%$ & $0.040 \%$ & $1.800 \%$ & $0.038 \%$ & $1.849 \%$ \\
\hline 2 & $0.058 \%$ & $1.947 \%$ & $0.058 \%$ & $1.896 \%$ & $0.052 \%$ & $1.839 \%$ & $0.051 \%$ & $1.869 \%$ \\
\hline 3 & $0.079 \%$ & $2.037 \%$ & $0.085 \%$ & $2.079 \%$ & $0.065 \%$ & $1.945 \%$ & $0.064 \%$ & $1.973 \%$ \\
\hline 4 & $0.099 \%$ & $2.183 \%$ & $0.112 \%$ & $2.343 \%$ & $0.078 \%$ & $2.103 \%$ & $0.077 \%$ & $2.138 \%$ \\
\hline 5 & $0.120 \%$ & $2.375 \%$ & $0.139 \%$ & $2.661 \%$ & $0.091 \%$ & $2.313 \%$ & $0.090 \%$ & $2.339 \%$ \\
\hline 6 & $0.140 \%$ & $2.627 \%$ & $0.166 \%$ & $3.048 \%$ & $0.104 \%$ & $2.560 \%$ & $0.103 \%$ & $2.584 \%$ \\
\hline 7 & $0.160 \%$ & $2.974 \%$ & $0.192 \%$ & $3.498 \%$ & $0.116 \%$ & $2.853 \%$ & $0.116 \%$ & $2.891 \%$ \\
\hline 8 & $0.181 \%$ & $3.410 \%$ & $0.219 \%$ & $4.108 \%$ & $0.129 \%$ & $3.209 \%$ & $0.129 \%$ & $3.236 \%$ \\
\hline 9 & $0.201 \%$ & $3.926 \%$ & $0.246 \%$ & $5.239 \%$ & $0.142 \%$ & $3.692 \%$ & $0.142 \%$ & $3.723 \%$ \\
\hline 10 & $0.221 \%$ & $6.824 \%$ & $0.273 \%$ & $6.923 \%$ & $0.155 \%$ & $6.556 \%$ & $0.155 \%$ & $6.556 \%$ \\
\hline
\end{tabular}

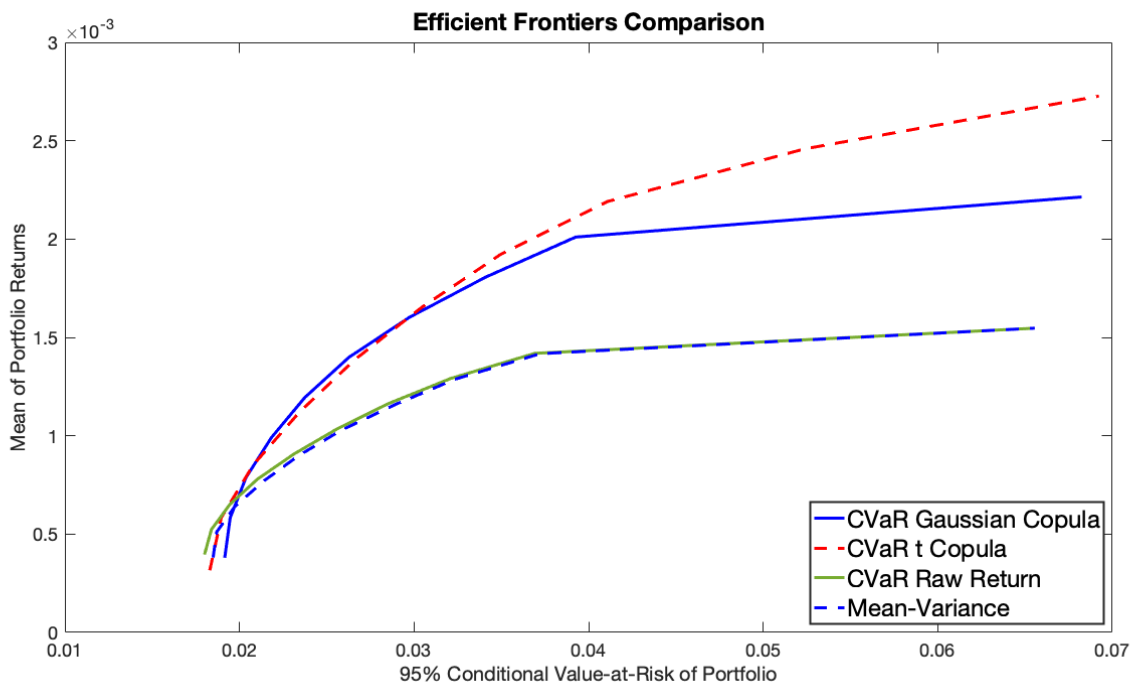

Figure 3. Mean-CVaR efficient frontiers with $95 \%$ CVaR (23 random stocks) 
two above figures. The Gaussian copula CVaR simulation frontier is higher than the $t$ copula $\mathrm{CVaR}$ frontier in the beginning, then this frontier traces below the $t$ copula CVaR curve. The results from $t$-copula simulation and Gaussian copula simulation with $\mathrm{CVaR}$ still surpass the results from historical $\mathrm{CVaR}$ optimization and Mean-Variance optimization. The historical raw return $\mathrm{CVaR}$ frontier is again always higher than the Mean-Variance efficient frontier.

\subsection{Portfolio optimization with $99 \%$ of conditional value at risk}

In the case of $99 \% \mathrm{CVaR}$ with the data input of full 43 stocks, the graph undergoes a simi- lar tendency with the graph of 95\% CVaR. The Gaussian copula shows the best results of portfolios with the low level of risk and with highest returns compared to other models. However, in this case, the $t$ copula CVaR frontier performs more efficient results of portfolios with the highest returns, but the CVaR level of these portfolios is undermost compared to the remaining portfolios. A portfolio with the superlative return in $t$ copula frontier holds the risk level equal to half of other portfolios' risk. In addition, the historical raw return CVaR frontier is also higher than the Mean-Variance frontier.

With the data input of the period of 6.5 years, the results showed the same trend as the other cases.

Table 4. Mean returns and $99 \%$ CVaR of 10 portfolios in each case

\begin{tabular}{|c|c|c|c|c|c|c|c|c|}
\hline \multirow{2}{*}{$\begin{array}{l}\text { Portfolio } \\
\text { number }\end{array}$} & \multicolumn{2}{|c|}{$\begin{array}{l}\text { Mean-CVaR under } \\
\text { Gaussian copula } \\
\text { simulation }\end{array}$} & \multicolumn{2}{|c|}{$\begin{array}{l}\text { Mean-CVaR under } t \\
\text { copula simulation }\end{array}$} & \multicolumn{2}{|c|}{$\begin{array}{c}\text { Mean- CVaR } \\
\text { with raw return }\end{array}$} & \multicolumn{2}{|c|}{$\begin{array}{l}\text { Mean-variance } \\
\text { with raw return }\end{array}$} \\
\hline & $\begin{array}{l}\text { Mean } \\
\text { return }\end{array}$ & 99\% CVaR & $\begin{array}{l}\text { Mean } \\
\text { return }\end{array}$ & 99\% CVaR & $\begin{array}{l}\text { Mean } \\
\text { return }\end{array}$ & 99\% CVaR & $\begin{array}{l}\text { Mean } \\
\text { return }\end{array}$ & 99\% CVaR \\
\hline 1 & $0.046 \%$ & $1.819 \%$ & $0.037 \%$ & $2.088 \%$ & $0.033 \%$ & $1.904 \%$ & $0.034 \%$ & $2.046 \%$ \\
\hline 2 & $0.064 \%$ & $1.844 \%$ & $0.058 \%$ & $2.141 \%$ & $0.050 \%$ & $1.978 \%$ & $0.051 \%$ & $2.155 \%$ \\
\hline 3 & $0.082 \%$ & $1.952 \%$ & $0.079 \%$ & $2.305 \%$ & $0.067 \%$ & $2.170 \%$ & $0.068 \%$ & $2.382 \%$ \\
\hline 4 & $0.100 \%$ & $2.155 \%$ & $0.099 \%$ & $2.584 \%$ & $0.084 \%$ & $2.483 \%$ & $0.085 \%$ & $2.688 \%$ \\
\hline 5 & $0.118 \%$ & $2.570 \%$ & $0.120 \%$ & $2.958 \%$ & $0.101 \%$ & $2.866 \%$ & $0.102 \%$ & $3.043 \%$ \\
\hline 6 & $0.136 \%$ & $3.247 \%$ & $0.141 \%$ & $3.432 \%$ & $0.118 \%$ & $3.332 \%$ & $0.119 \%$ & $3.490 \%$ \\
\hline 7 & $0.154 \%$ & $4.199 \%$ & $0.162 \%$ & $3.984 \%$ & $0.135 \%$ & $3.881 \%$ & $0.135 \%$ & $4.008 \%$ \\
\hline 8 & $0.172 \%$ & $5.899 \%$ & $0.182 \%$ & $4.680 \%$ & $0.152 \%$ & $4.624 \%$ & $0.152 \%$ & $4.716 \%$ \\
\hline 9 & $0.190 \%$ & $8.773 \%$ & $0.203 \%$ & $5.634 \%$ & $0.169 \%$ & $6.853 \%$ & $0.169 \%$ & $7.014 \%$ \\
\hline 10 & $0.208 \%$ & $12.311 \%$ & $0.224 \%$ & $7.327 \%$ & $0.186 \%$ & $12.338 \%$ & $0.186 \%$ & $12.338 \%$ \\
\hline
\end{tabular}

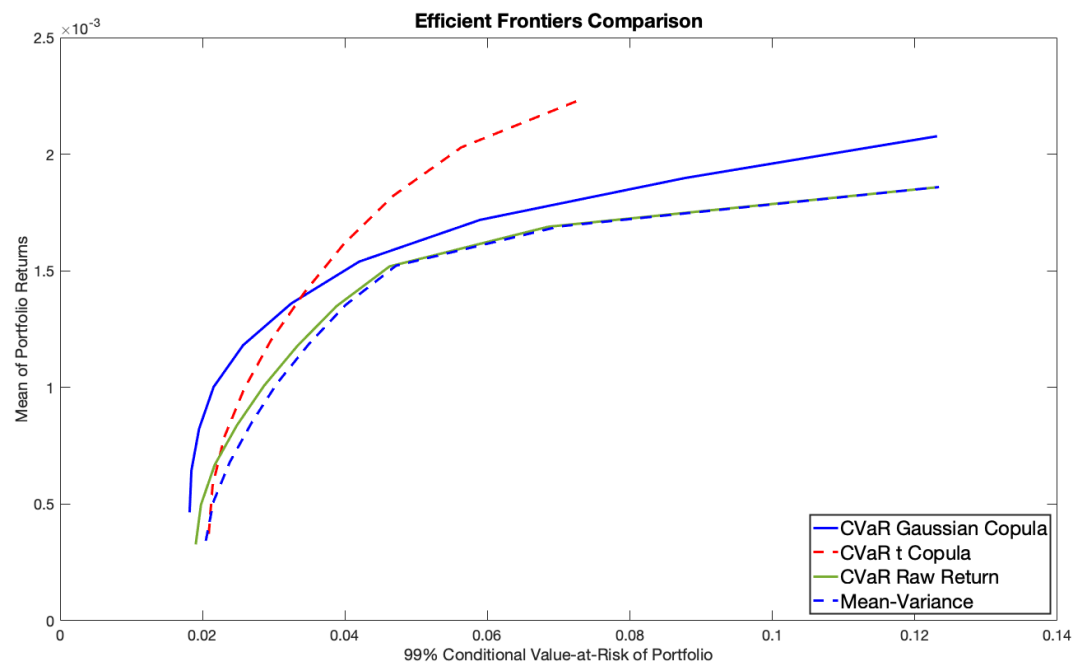

Figure 4. Mean-CVaR efficient frontiers with the $99 \%$ CVaR 
Table 5. Mean returns and $99 \%$ CVaR of 10 portfolios in each case (6.5-year duration)

\begin{tabular}{|c|c|c|c|c|c|c|c|c|}
\hline \multirow{2}{*}{$\begin{array}{l}\text { Portfolio } \\
\text { number }\end{array}$} & \multicolumn{2}{|c|}{$\begin{array}{l}\text { Mean-CVaR under Gaussian } \\
\text { copula simulation }\end{array}$} & \multicolumn{2}{|c|}{$\begin{array}{l}\text { Mean-CVaR under } t \\
\text { copula simulation }\end{array}$} & \multicolumn{2}{|c|}{$\begin{array}{c}\text { Mean- CVaR } \\
\text { with raw return }\end{array}$} & \multicolumn{2}{|c|}{$\begin{array}{l}\text { Mean-variance } \\
\text { with raw return }\end{array}$} \\
\hline & Mean return & 99\% CVaR & $\begin{array}{l}\text { Mean } \\
\text { return }\end{array}$ & 99\% CVaR & $\begin{array}{l}\text { Mean } \\
\text { return }\end{array}$ & 99\% CVaR & $\begin{array}{l}\text { Mean } \\
\text { return }\end{array}$ & 99\% CVaR \\
\hline 1 & $0.056 \%$ & $1.496 \%$ & $0.028 \%$ & $1.504 \%$ & $0.048 \%$ & $1.454 \%$ & $0.039 \%$ & $1.677 \%$ \\
\hline 2 & $0.078 \%$ & $1.518 \%$ & $0.069 \%$ & $1.570 \%$ & $0.067 \%$ & $1.532 \%$ & $0.059 \%$ & $1.723 \%$ \\
\hline 3 & $0.100 \%$ & $1.629 \%$ & $0.111 \%$ & $1.735 \%$ & $0.086 \%$ & $1.703 \%$ & $0.079 \%$ & $1.867 \%$ \\
\hline 4 & $0.122 \%$ & $1.831 \%$ & $0.152 \%$ & $2.058 \%$ & $0.105 \%$ & $1.934 \%$ & $0.099 \%$ & $2.062 \%$ \\
\hline 5 & $0.144 \%$ & $2.118 \%$ & $0.193 \%$ & $2.508 \%$ & $0.124 \%$ & $2.236 \%$ & $0.119 \%$ & $2.371 \%$ \\
\hline 6 & $0.166 \%$ & $2.493 \%$ & $0.235 \%$ & $3.062 \%$ & $0.143 \%$ & $2.645 \%$ & $0.139 \%$ & $2.784 \%$ \\
\hline 7 & $0.188 \%$ & $2.922 \%$ & $0.276 \%$ & $3.720 \%$ & $0.162 \%$ & $3.146 \%$ & $0.159 \%$ & $3.300 \%$ \\
\hline 8 & $0.209 \%$ & $3.487 \%$ & $0.318 \%$ & $4.495 \%$ & $0.181 \%$ & $3.694 \%$ & $0.179 \%$ & $3.970 \%$ \\
\hline 9 & $0.231 \%$ & $4.543 \%$ & $0.359 \%$ & $5.509 \%$ & $0.200 \%$ & $4.506 \%$ & $0.200 \%$ & $4.621 \%$ \\
\hline 10 & $0.253 \%$ & $6.985 \%$ & $0.401 \%$ & $6.980 \%$ & $0.220 \%$ & $6.451 \%$ & $0.220 \%$ & $6.451 \%$ \\
\hline
\end{tabular}

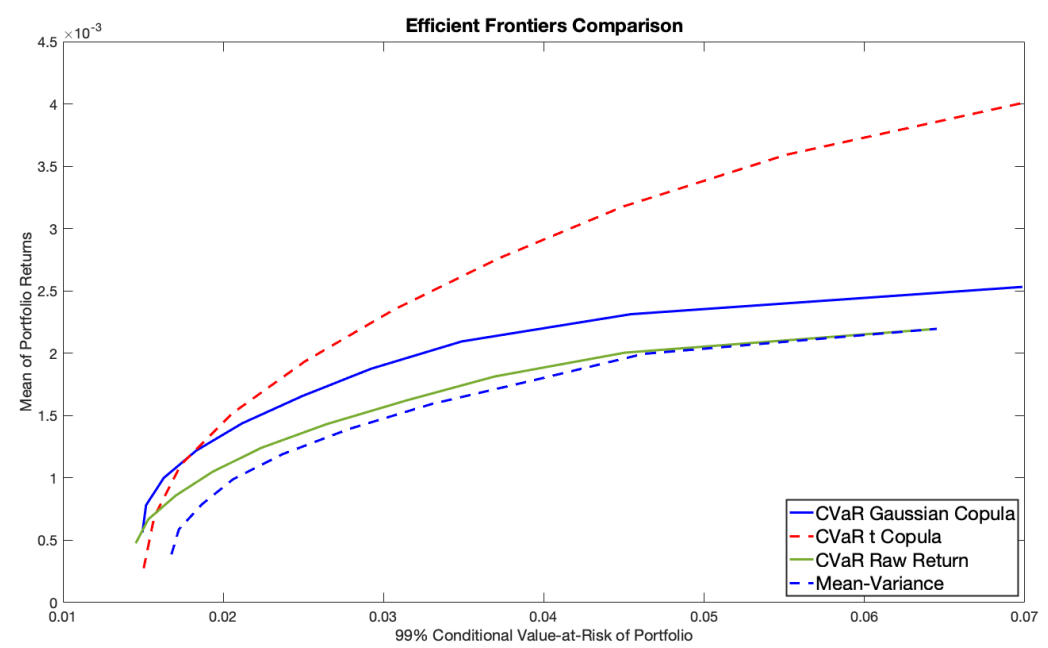

Figure 5. Mean-CVaR efficient frontiers with 99\% CVaR (6.5-year duration)

Table 6. Mean returns and $99 \%$ CVaR of 10 portfolios in each case (23 random stocks)

\begin{tabular}{|c|c|c|c|c|c|c|c|c|}
\hline \multirow{2}{*}{$\begin{array}{c}\text { Portfolio } \\
\text { number }\end{array}$} & \multicolumn{2}{|c|}{$\begin{array}{l}\text { Mean-CVaR under Gaussian } \\
\text { copula simulation }\end{array}$} & \multicolumn{2}{|c|}{$\begin{array}{l}\text { Mean-CVaR under } t \\
\text { copula simulation }\end{array}$} & \multicolumn{2}{|c|}{$\begin{array}{c}\text { Mean- CVaR } \\
\text { with raw return }\end{array}$} & \multicolumn{2}{|c|}{$\begin{array}{l}\text { Mean-variance } \\
\text { with raw return }\end{array}$} \\
\hline & Mean return & 99\% CVaR & $\begin{array}{l}\text { Mean } \\
\text { return }\end{array}$ & 99\% CVaR & $\begin{array}{l}\text { Mean } \\
\text { return }\end{array}$ & $99 \%$ CVaR & $\begin{array}{l}\text { Mean } \\
\text { return }\end{array}$ & 99\% CVaR \\
\hline 1 & $0.034 \%$ & $2.453 \%$ & $0.036 \%$ & $2.468 \%$ & $0.038 \%$ & $2.396 \%$ & $0.038 \%$ & $2.568 \%$ \\
\hline 2 & $0.055 \%$ & $2.489 \%$ & $0.063 \%$ & $2.546 \%$ & $0.051 \%$ & $2.475 \%$ & $0.051 \%$ & $2.621 \%$ \\
\hline 3 & $0.075 \%$ & $2.573 \%$ & $0.089 \%$ & $2.775 \%$ & $0.064 \%$ & $2.607 \%$ & $0.064 \%$ & $2.743 \%$ \\
\hline 4 & $0.096 \%$ & $2.729 \%$ & $0.115 \%$ & $3.101 \%$ & $0.077 \%$ & $2.822 \%$ & $0.077 \%$ & $2.939 \%$ \\
\hline 5 & $0.117 \%$ & $2.970 \%$ & $0.141 \%$ & $3.555 \%$ & $0.090 \%$ & $3.079 \%$ & $0.090 \%$ & $3.197 \%$ \\
\hline 6 & $0.138 \%$ & $3.321 \%$ & $0.168 \%$ & $4.096 \%$ & $0.103 \%$ & $3.428 \%$ & $0.103 \%$ & $3.522 \%$ \\
\hline 7 & $0.159 \%$ & $3.819 \%$ & $0.194 \%$ & $4.830 \%$ & $0.116 \%$ & $3.815 \%$ & $0.116 \%$ & $3.947 \%$ \\
\hline 8 & $0.180 \%$ & $4.437 \%$ & $0.220 \%$ & $5.757 \%$ & $0.129 \%$ & $4.315 \%$ & $0.129 \%$ & $4.416 \%$ \\
\hline 9 & $0.201 \%$ & $5.141 \%$ & $0.246 \%$ & $6.936 \%$ & $0.142 \%$ & $4.882 \%$ & $0.142 \%$ & $4.989 \%$ \\
\hline 10 & $0.221 \%$ & $7.802 \%$ & $0.273 \%$ & $8.819 \%$ & $0.155 \%$ & $7.064 \%$ & $0.155 \%$ & $7.064 \%$ \\
\hline
\end{tabular}

The results of the optimizational models of 23 random stocks selected from the research sample of 43 stocks with $99 \%$ CVaR perform the same outcome as the previous analyses. However, in this case, with the CVaR level lower than $0.45 \%$, the
Gaussian copula CVaR frontier is higher than the frontier of $t$ copula CVaR simulation. After the risk level of $0.45 \%$ CVaR, the $t$ copula CVaR simulation frontier has better performance than the other three frontiers. 


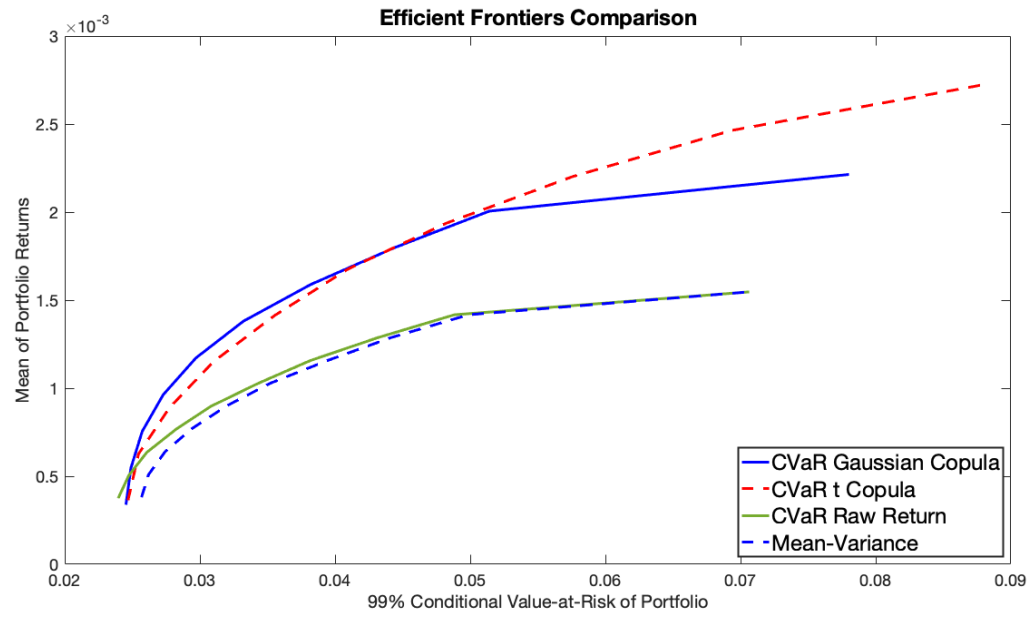

Figure 6. Mean-CVaR efficient frontiers with $99 \%$ CVaR (23 random stocks)

\section{CONCLUSION}

This study has constructed and analyzed optimal portfolios for investors in the Vietnamese market. To find an optimal portfolio, four frameworks were used such as the Mean-CVaR approach and simulated with $t$ copula and Gaussian copula, as well as the traditional Mean-Variance framework. Empirical results show that in the context of the Vietnamese stock exchange, the Mean-CVaR framework generally scores better than the Mean-Variance framework. Furthermore, the frontiers of portfolios simulated with copulas have superior results than the frontiers of historical raw return CVaR portfolios and MeanVariance portfolios in both cases of $95 \% \mathrm{CVaR}$ and $99 \% \mathrm{CVaR}$. In addition, it can be observed that if the risk aversion of investors is low, the Gaussian copula CVaR simulation exposes better results compared to other cases. Overall, however, portfolios simulated using the $t$ copula CVaR framework have the superlative results across the four models in terms of both return and risk.

In practice, the results of this study can help individual investors with better investment knowledge to limit risk and gain profit throughout this research. The study can also be a worthy recommendation for investors to make reasonable investment decisions, avoiding choosing stocks with high volatility or low returns that adversely affect their portfolios.

From an academic point of view, this paper also proved the consistent outcome of the new approach with copula simulation of Mean-CVaR framework on the particular data of the Vietnamese stock exchange, not only in different time frames, but also with disparate data inputs. This paper confirms the hypothesis that the CVaR portfolio optimization framework simulated with copulas performs better than the historical raw return CVaR framework and Mean-Variance framework in terms of empirical results in the context of the Vietnamese stock market.

\section{AUTHOR CONTRIBUTIONS}

Conceptualization: Le Tuan Anh, Dao Thi Thanh Binh.

Data curation: Le Tuan Anh.

Formal analysis: Le Tuan Anh.

Investigation: Le Tuan Anh, Dao Thi Thanh Binh.

Methodology: Le Tuan Anh, Dao Thi Thanh Binh. 
Project administration: Le Tuan Anh.

Resources: Le Tuan Anh.

Software: Le Tuan Anh.

Supervision: Dao Thi Thanh Binh.

Validation: Le Tuan Anh, Dao Thi Thanh Binh.

Visualization: Le Tuan Anh.

Writing - original draft: Le Tuan Anh.

Writing - review \& editing: Le Tuan Anh, Dao Thi Thanh Binh.

\section{REFERENCES}

1. Alexander, S., Coleman, T. F., \& Li, Y. (2006). Minimizing CVaR and VaR for a Portfolio of Derivatives. Journal of Banking and Finance, 30(2), 583-605. https://doi.org/10.1016/j.jbankfin.2005.04.012

2. Andersson, F., A., Mausser, H., Rosen, D., \& Uryasev, S. (2001). Credit Risk Optimization with Conditional Value-atRisk Criterion. Mathematical Programming, 89(2), 273-291. Retrieved from https://link. springer.com/article/10.1007/ PL00011399

3. Artzner, P. F.-M. (1999). Coherent Measures of Risk. Mathematical Finance, 9(3), 203-228. https://doi. org/10.1111/1467-9965.00068

4. Chen, A. H., Fabozzi, F. J., \& Huang, D. (2012). Portfolio Revision under MeanVariance and Mean-CVaR with Transaction Costs. Review of Quantitative Finance and Accounting, 39(4), 509-526. Retrieved from https:// ink.library.smu.edu.sg/lkcsb_research/4785/

5. Chirag Shekhar, \& Mark Trede. (2017). Portfolio Optimization Using Multivariate t-Copulas with Conditionally Skewed Margins. Review of Economics \& Finance. Retrieved from https:// econpapers.repec.org/article/bapjournl/170303.htm

6. Cuong Thanh NGUYEN, M. H. (2019). Modeling Stock Price Volatility: Empirical Evidence from the Ho Chi Minh City Stock Exchange in Vietnam. Journal of Asian Finance, Economics and Business, 6(3), 19-26. https://doi. org/10.13106/jafeb.2019.vol6. no3.19
7. Dao, B. T. (2014). Optimal Portfolio with Options in a Framework of Mean-CVaR. SSRN Electronic Journal. Retrieved from https://papers.ssrn.com/sol3/papers.cfm?abstract_id=2543722

8. Hafsa, H. (2015). CVaR in Portfolio Optimization: An Essay on the French Market. International Journal of Financial Research, 6(2). https://doi. org/10.5430/ijfr.v6n2p101

9. Hu, J. (2012). An Empirical Comparison of Different Approaches in Portfolio Selection (U.U.D.M. Project Report 2012:7). Retrieved from https:// uu.diva-portal.org/smash/get/ diva2:529501/FULLTEXT01.pdf

10. Isaksson, D. (2016). Robust Portfolio Optimization with Expected Shortfall. Retrieved from http://kth.diva-portal.org/smash/ record.jsf?pid=diva2\%3A934147\& $\mathrm{dswid}=6030$

11. Iyengar, Garud, \& Ka, Alfred. (2009). Fast gradient descent method for Mean-CVaR optimization. Annals of Operations Research, 205. Retrieved from https://ideas.repec.org/a/spr/annopr/v205y2013i1p203-21210.1007s10479-012-1245-8.html

12. Kakouris, I., \& Rustem, B. (2013). Robust Portfolio Optimization with Copulas. European Journal of Operational Research, 235(1), 28-37. https://doi.org/10.1016/j. ejor.2013.12.022

13. Kolm, P. N., Tutuncu, R., \& Fabozzi, F. J. (2014). 60 Years of Portfolio Optimization: Practical Challenges and Current Trends. European Journal of Operational Research, 234(2), 356-371. https:// doi.org/10.1016/j.ejor.2013.10.060
14. Krokhmal, P. J. (2002). Portfolio Optimization With Conditional Value-At-Risk Objective and Constraints. Journal of Risk, 4 , 43-68. http://dx.doi.org/10.21314/ JOR.2002.057

15. Krzemienowski, A., \& Szymczyk, S. (2016). Portfolio optimization with a copula-based extension of conditional value-at-risk. Annals of Operations Research. Retrieved from https://link.springer.com/article/10.1007/s10479-014-1625-3

16. Lim, A., Shanthikumar, J., \& Vahn, G. (2009). Fragility of $\mathrm{CVaR}$ in portfolio optimization. UC Berkeley: Center for Risk Management Research. Retrieved from https://escholarship.org/uc/ item/5pp7z1z8

17. Linh H. Nguyen, Linh X. D. Nguyen, \& Emmanuel Adegbite. (2018). Does Mean-CVaR Outperform Meanvariance? Theoretical and Practical Perspectives. Retrieved from https:// papers.ssrn.com/sol3/papers. cfm?abstract_id=3143827

18. Markowitz, H. (1952). Portfolio Selection. Journal of Finance, 7(1), 77-91. https://doi. org/10.1111/j.1540-6261.1952. tb01525.x

19. Markowitz, H. (1959). Portfolio Selection: Efficient Diversification of Investments (pp. 95-112). New York: John Wiley Sons. Retrieved from https://www.jstor.org/stable/j. ctt1bh4c8h

20. Nhat NGUYEN, Trung NGUYEN, Tuan TRAN, \& An Mai. (2020). Shrinkage Model Selection for Portfolio Optimization on Vietnam Stock Market. Journal of Asian Finance, Economics and Business, 7(9), 135-145. http:// dx.doi.org/10.13106/jafeb.2020.vol7. no9.135 
21. Rockafellar, R. T., \& Uryasev, S. (2000). Optimization of Conditional Value-at-Risk. Journal of Risk, 2, 21-42. Retrieved from https://www.risk.net/journalrisk/2161159/optimization-conditional-value-risk

22. Rockafellar, R. T., \& Uryasev, S. (2002). Conditional Valueat-Risk for General Loss Distributions. Journal of Banking and Finance, 26(7), 1443-1471. https://doi.org/10.1016/S03784266(02)00271-6
23. Topaloglou, Nikolas, Hercules Vladimirou, \& Stavros A. Zenios. (2002). CVaR Models with Selective Hedging for International Asset Allocation. Journal of Banking and Finance, 26(7), 15351561. https://doi.org/10.1016/ S0378-4266(02)00289-3

24. Trabelsi, N., \& Tiwari, A. K. (2019). Market-Risk Optimization among the Developed and Emerging Markets with CVaR Measure and Copula Simulation. Risks, 7(3), 78. https://doi.org/10.3390/ risks 7030078
25. Xubiao He, Pu Gong. (2007). Measuring the coupled risks: A copula-based CVaR model. Journal of Computational and Applied Mathematics, 223(2), 1066-1080. https://doi. org/10.1016/j.cam.2008.03.046

26. Zhang, Q. (2016). Multiportfolio Optimization with CVaR Risk Measure. Electronic Theses and Dissertations, 5685. Retrieved from https://scholar.uwindsor. $\mathrm{ca} / \mathrm{etd} / 5685 /$ 